УДК 78.03+78.05/78.072.2

\title{
C. Осадиая
}

\section{ЯВЛЕНИЕ И ПОНЯТИЕ КАНОНА КАК ОСНОВА ПРАВОСЛАВНОЙ БОГОСЛУЖЕБНО-ПЕВЧЕСКОЙ ТРАДИЦИИ: ОТ КАНОНИЧЕСКОЙ ФОРМЫ К «ДУХУ ТВОРЧЕСТВА»}

\begin{abstract}
Статья посвящена рассмотрению явления и понятия канона как основы православной певческой традиции. Выявляется, что каноническую форму следует понимать как форму, созданную внутри традиции, внутри жизни канона и под его непосредственным влиянием, что позволяет рассматривать канон как необходимую основу для богослужебно-певческого творчества.
\end{abstract}

Ключевые слова: канон, каноническая форма, богослужебно-певческая традиция, культ, церковность.

Теория богослужебного пения исходит из предписаний, теоретических объяснений певческого поведения в храме, таким образом, тесно связана с прагматикой обряда и его каноническими сторонами, постепенно углубляющимися до формирования собственно музыкальных - певческих канонов. По учению святых отцов и учителей Церкви, церковное пение должно возбуждать усердие и внимание христиан к священным песнопениям, а также готовность воспринимать их полезное содержание. Подтверждение этого мы находим у святителя Василия Великого, епископа Кесарии Каппадокийской: «Дух Святый знал, что трудно вести род человеческий к добродетели, и что по склонности к удовольствию мы нерадим о правом пути. Итак: что же делает? К учениям примешивает приятность сладкопения, чтобы вместе с усладительным и благозвучным для слуха принимали мы неприметным образом и то, что есть полезного в слове» [2, с. 94]. Св. Василий Великий указывал на необычайно умиротворяющее и поучительное действие псалмопения, чтобы поющие «по-видимому только пели их, а в действительности обучали свои души», так как «псалом - тишина душ, раздаятель мира; он утишает мятежные и волнующие помыслы; он смягчает раздражительность души и уцеломудривает невоздержанность... Псалом занятие Ангелов, небесное сожительство, духовный фимиам. Это мудрое изобретение Учителя, устроившего, чтобы мы пели, и вместе учились полезному. От сего и уроки лучше напечатлеваются в

(C) Осадчая С., 2016 
душах. Ибо с принуждением выучиваемое не остается в нас надолго; а что с удовольствием и приятностию принято, то в душах укореняется тверже» [2, с. 95-96].

Наряду с разъяснительным и воспитательным влиянием богослужебного пения в святооотеческом наследии есть немало указаний на его умиротворяющее, возвышающее воздействие. Примером этого может служить высказывание св. Афанасия Великого, архиепископа Александрийского, который в своем сочинении «О псалмах, против Маркеллиана» развил мысль о силе воздействия и о месте и значении псалмопения в богослужении.

Таким образом, если обратиться к опыту людей, достигших, по мнению Православной церкви, самых высоких степеней духовного развития, - к опыту святых, то можно увидеть, что они шли путем церковности, жизни в культе. Иными словами, их путь представлял собой, в первую очередь, жизнь внутри церковного обряда.

Вслед за византийским православием православие, установившееся на территории Киевской Руси, сочетает склонность к философскому рассмотрению религии с высокой оценкой важности обряда. Как отмечал о. Павел Флоренский, «вместе с разработанной теософией, где выясняются в философских терминах отношения между Лицами Пресвятой Троицы, между естествами в Богочеловеке, понятия Церкви, спасения, бессмертия и т. п., в восточной религиозности не меньшее значение имеет глубокое уважение к обряду, так что исполнение его ставится рядом и даже выше исполнения нравственных заветов» [5, с. 468]. Иными словами, соблюдение в неприкосновенности и во всех подробностях обряда становится одной из главных забот церкви. Это пристальное внимание распространяется и на певческую сторону обряда, в особенности на исполнение всех обрядов связанных с рождением, браком и со смертью человека. Таким образом, отличительная черта православного отношения к Церкви это перевес участия в культе и обряде над любыми нравоучительными действиями: непосредственное участие в церковной жизни гораздо важнее сухого изучения богослужения по книгам. В свою очередь, культ и православный обряд необычайно внимателен к наиболее важным моментам жизни человека - «рождение, смерть, брак происходят пред лицом Бога и благословляются таинствами и богослужениями» [5, с. 478].

Система обрядов образует замкнутое целое, в котором замена одного обряда другим невозможна, так как таковая замена непремен- 
но потрясет основы всей системы. «Нельзя в организме произвольно заменить орган таковым же, иного типа, ибо с изменением органа должны соответственно измениться и все прочие» [7, с. 158]. В культе, на пути восхождения от земного к небесному, обряд понимается Флоренским как постепенность умираний земного, а на пути нисхождения небесного к земному - как воплощение в земном. В обряде нет статики, он полон движения, взаимопроникновения и взаимодействия. Но в культе есть еще один вид постоянного движения, в котором происходит постоянное восхождение к горнему и нисхождение к дольнему.

Понятие святости имеет полюс нижний и полюс верхний, и в нашем сознании движется между этими полюсами, восходя вверх и нисходя обратно. Понятие святости - как лестница: небытие мир - исключение - избрание - очищение - искупление - Свет Бог. В движении по этой «лестнице» особую роль играют Свидетели. Флоренский указывает, что в христианском понимании свидетельство и мученичество - слова и явления одного корня, что и объясняет важное значение свидетельства в Новом Завете. В связи с этим вновь возникает мотив святости: мученики - святые и наоборот. Подвиг жизни внутренне есть всегда мученичество; сакральному нужны свидетели. Оно нуждается в проводниках, в передаче, в свидетельстве: наличие свидетельства делает сакральное удостоверенным [3, c. 162-167].

Кроме того, смысловое значение переводов греческого слова $\mu \alpha \rho \tau v \varsigma$, которое на греческом языке означает «свидетель», на церковно-славянском звучит как «мученик», можно разделить на две груп-

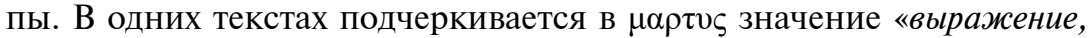
утверждение истины», в других текстах — «страдание и смерть». Эта двойственность переводов выявляет особенность данного греческого слова, в основе которого лежат (или могут лежать) три корня, а именно: $\mu \alpha \rho-$ сиять, $\mu \alpha \rho-$ бороться, $\mu \varepsilon \rho-$ иметь мысль, памятовать. Все данные смысловые оттенки находят свое отображение в слове $\mu \alpha \rho \tau \nu \varsigma-$ свидетель, мученик. Флоренский говорит о двух силах проявления свидетельствования - вовне и внутри. «Свидетельствование об истине есть сияние. Но, чтобы свидетельствовать об истине - надо бороться, побеждая тьму неведения и лжи: свидетель есть бореи и, духовно, победитель. При борьбе же - приходится не только наносить, но и получать удары, а потому - страдать, мучиться, изнемогать, и даже умирать» [7, с. 363]. Это о. Павел называет прояв- 
лением силы свидетельствования вовне. Чтобы свидетельствовать со стороны внутренней, свидетелю-мученику «надо иметь в себе свидетельствуемую истину», быть «владеемым истиной, носителем истины», иными словами «объективная истина заставляет памятовать о себе и властно ведет познавшего ее к свидетельствованию о ней» (выделение наше - C. O.) [7, с. 363]. Мученичество являет собой особый символ живого взаимного проникновения двух «бытий» - земного и небесного.

Символические основы литургической деятельности обусловлены тем, что служба осуществляется как платоновское «припоминание», в ней есть «что-то глубоко-глубоко близкое, что-то давно знакомое» [7, с. 131]. Она древнее нас и наших родителей, древнее человечества, древнее самого мира; поэтому она предполагает «умное делание» сущность умной молитвы. Служба была словно не сочинена, а открыта, обретена. «Православие вобрало самый цвет мирового достояния и освободило от шелухи и оболочек: у нас - чистое, обмолоченное и провеянное, зерно религий, самая суть человечности» [7, с. 131]. Примечательно, что семитский трехбуквенный корень, обозначающий в переводе на русский язык припоминать, помнить, в основном своем значении переводится как «призывать в культе». Таким образом, понятие о памятовании оказывается «не более как рефлексом культового поминовения, и память вообще - применением к человеку того, что собственно относится к Богу, ибо Ему Одному свойственно помнить в истинном значении слова» [6, с.172].

«О чем просил с креста благоразумный разбойник? - «Помяни мя, Господи, егда придешь во Царствии Твое», просит помянуть, и только» (Лк. 23, 42) [6, с. 173]. Разбойник просит быть помянутым не здесь на земле, он кротко просит быть помянутым в Царствии Божием. Иными словами, он не просит спасения телу - он надеется на спасение души. На его просьбу Господь отвечает: «истинно говорю тебе, днесь со мною будешь в раю» (Лк. 23, 43). Таким образом, «быть помянутым» Господом - это то же, что «быть в раю». «Быть в раю» это и значит быть бытием в вечной памяти, как следствие этого, иметь вечное существование и вечную память о Боге: без памятования о Боге мы умираем, но самое-то наше памятование о Боге возможно через памятование Бога о нас» [6, с. 173]. Следовательно, на основании вышесказанного можно сделать вывод, что вечная память Бога о нас и нас о Боге сходятся и реализуются в вечной памяти Церкви, в которой присутствует Бог и может находиться человек. 
Опираясь на положения трудов о. Павла Флоренского, мы можем выделить ряд понятий, которые имеют непосредственное отношение к богослужебно-певческой традиции и раскрывают концепцию «музыки богослужения», что позволяет определять православную певческую традицию как «самовозрастающий логос». Целью художества, понимаемого как совокупность всех проявлений искусств, Флоренский видит преодоление «натуралистической коры случайного» и формирование «общеценного и общезначимого в действительности». Иными словами, целью любого искусства (художества) становится стремление к преображению действительности. Применительно к церковным искусствам такого рода деятельность полноценно может быть воплощена только в культе. Само понятие культа по Флоренскому, может быть выделено как одно из самых важных для правильного понимания того, что представляет собой «музыка богослужения». Флоренский определяет культ как выделенную часть реальности, где встречаются имманентное и трансцендентное, временное и вечное, тленное и нетленное. Возможно, эта «встреча» явно выражена и в музыкальной культуре в целом, но наибольшую выразительность она приобретает именно в «музыке богослужения», которую он именует «концентрированным опытом». Для «музыки богослужения» типичным является сосредоточение всех установок православного богослужения, которые по своей сути всегда были «культоцентричны». «Истинная реальность - в отношении которой и может быть речь о самоопределении - одна: это реализованный смысл или осмысленная реальность, это - воплощенный Логос, это - культ» [7, с. 104].

Еще одним необходимым условием существования храмового действа как единого организма является наличие канона. Флоренский считает одной из наиболее жизненных задач - постигнуть суть и смысл канона, однако необходимое условие для этого - причастность к нему. «Ближайшая задача - постигнуть смысл канона, изнутри проникнуть в него как в сгущенный разум человечества» (курсив наш. - C. О.) [4, с. 557]. Истинный художник, по мнению Флоренского, хочет не своего, не создания чего-либо эгоистично-индивидуального во что бы то ни стало, истинный художник стремится к созданию действительно прекрасного, «объективно-прекрасного», то есть «художественно воплощенной истины вещей» [4, с. 556]. При условии, что это действительно истина, ценность произведения, как считает Флоренский, установится сама собой. Истинным произве- 
дение может быть только в общем потоке всечеловеческой истории; нарочито выдуманное истинным не является, то есть оно не является каноническим. Принятие канона - это ощущение неразрывной связи с человечеством, и сознание наследования всех тех сокровищ, которые были созданы прошлыми поколениями творцов. «Проверенное и очищенное собором народов и поколений» [4, с. 557], самое ценное и истинное было закреплено в каноне. Следовательно, канон действительно можно назвать «сгущенным разумом человечества».

Чем онтологичнее видение художника, тем общечеловечнее, каноничнее форма, в которой будет выражено его видение. «Каноническая форма - это форма наибольшей естественности, то, проще чего не придумаешь, тогда как отступление от форм канонических стеснительны и искусственны. Напротив, в канонических формах дышится легко: они отучают от случайного, мешающего в деле, движения. Чем устойчивее и тверже канон, тем глубже и чище он выражает общечеловеческую духовную потребность: каноническое есть церковное, церковное - соборное, соборное же - всечеловеческое» [4, с. 562]. Каноническая форма понимается как форма, созданная внутри традиции, внутри жизни канона и под его непосредственным влиянием; она строится веками, отсеивая случайное и фиксируя истинное. Так, каноны в области церковных песнопений, равно как и в области древней иконописи, создавались и выкристаллизовывались на протяжении столетий, при этом образуя особую грань канона, в которой отражается взаимоотношение слова и напева. Форма песнопений неотделима от содержащегося в ней духовного содержания, воплощенного в словах великими гимнотворцами и Отцами Церкви.

Значительная часть светских историков и «позитивистических богословов», как подчеркивает Флоренский, в нормах церковного сознания склонны усматривать «свойственный Церкви обычный ее консерватизм, старческое удержание привычных форм и приемов» [4, с. 556], однако это, по мнению Флоренского, является выражением непонимания как церковного консерватизма, так и непонимания сути художественного творчества. Для художественного творчества канон никогда не был помехой, и «трудные канонические формы во всех отраслях искусства всегда были только оселком, на котором ломались ничтожества и заострялись настоящие дарования» [4, с. 556]. Как подчеркивает о. Павел Флоренский, каноническая форма высвобождает творческую индивидуальность и творческую энергию художника - «требования канонической формы или, точнее, дар от 
человечества художнику канонической формы есть освобождение, а не стеснение» [4, с. 556]. Таким образом, через принятие канона осуществляется связь с человечеством и постижение истины, проверенной и очищенной собором народов и поколений. Поэтому «музыка богослужения» не стремится к созданию своего, индивидуально-личностного, ее целью является создание «художественно воплощенной истины вещей», которая может жить полноценно только как часть единого организма храмового действа. Каноническая форма «музыки богослужения» формировалась и выкристаллизовывалась вековой традицией, внутри жизни канона и под его непосредственным влиянием. Причем церковно-певческий канон представляет особую область взаимоотношений слова и напева: форма песнопения не может быть отделена от его духовного содержания.

Мировоззрение о. Павла Флоренского опирается на понимание сущего, в котором все проявления человеческой культуры находятся в неразрывной связи - как разные грани, разные аспекты раскрытия единой Истины. В своих размышлениях об искусстве, в частности о музыкальном искусстве, Флоренский выдвигает ряд положений, основывающихся на коренном убеждении - прекрасное есть истинное. Истинное «реалистическое» искусство создает символы вещей, тогда как мнимое искусство - их иллюзорные подобия.

Размышления о путях развития христианской культуры, о соотнесении канонических правил и жизни культа мы также можем найти в работах И. Ильина, в частности в работе «Основы христианской культуры» [1]. Ильин рассматривает всю историю христианства как «единый и великий поиск христианской культуры» [1, с. 22], подчеркивая, что это «великий поиск», в котором, безусловно, присутствуют и крайние взгляды на то, что такое христианская культура. «Одни, готовые отвергнуть во имя Христа земную культуру и самый мир, в пределах которого она создается; и другие, готовые принять слишком много земного и мирского, вплоть до утраты Христова Духа» [1, с. 22]. Единственно правильный путь, по мнению Ильина, - это «жизненно мудрый путь, который верно вел бы от Христа к миру, - укореняясь во Христе и творчески пропитывая Его лучами ткань человеческой жизни» [1, с. 22]. Ильин подчеркивает, что понимание Евангелия как «книги законов», в которой содержится система «определенных правил на все жизненные случаи и житейские затруднения» [1, с. 23], совершенно противоречит духу христианства. «Евангелие есть книга веры, свободы и совести, а не книга законов и правил. Евангелие надо 
читать и разуметь жмивым духом, глубиною своей собственной веры, своей свободы и своей совести, а не формальным рассудком» [1, c. 23]. Священное писание Нового Завета содержит в себе некий «благодатный и свободный дух», который является не замкнутым сводом правил, но несет в себе «живой поток любви и видения, вливающийся в душу и видения, вливающийся в душу и пробуждающий в ней глубочайшие истоки личной духовности; этот поток проникает в нас и освобождает нас к самостоятельному видению, решению и творчеству» [1, с. 23-24]. Таким образом, дух христианства является духом живого творческого содержания, где первостепенным становится именно содержание, а не форма. Однако это следует понимать не как оппозицию, не как противопоставление, но в том смысле, что категорически отметается преобладание «пустой, отвлеченной, самодовлеющей формы, лишенной насыщающего ее и освящающего ее содержания» [1, с. 33]. Следовательно в христианстве закон «не отметается, но наполняется живым и глубоким содержанием духа, так что «форма перестает быть «формою», а становится живым способом содержательной жизни, добродетелью, художеством, знанием - всею полнотою и богатством культурного бытия» [1, с. 33].

\section{СПИСОК ЛИТЕРАТУРЫ}

1. Ильин И. Основы христианской культуры / И. Ильин. - СПб. : Шпиль, 2004. -352 c.

2. Св. Василий Великий. Избранные творения / Св. Василий Великий. М. : Сретенский монастырь, 2006. - 498 с.

3. Флоренский П. Из богословского наследия / П. Флоренский // Богословские труды. Вып. 9. - М., 1972. - С. 85-248.

4. Флоренский П. Иконостас / П. Флоренский // Христианство и культуpa. - М. : Аст, 2001. - С. 521-627.

5. Флоренский П. Православие / П. Флоренский // Христианство и культура. - М. : Аст, 2001. - С. 465-490.

6. Флоренский П. Столп и утверждение истины: Опыт православной теодицеи / П. Флоренский. - М. : ООО «Издательство АСТ», 2003. - 640 с.

7. Флоренский П. Философия культа / П. Флоренский. - М. : Мысль, 2004. - 685 c.

Осадиа С. Явище та поняття канону як основи православної богослужбовоспівочої традицї: від канонічної форми до «духу твориості». Стаття присвячена розгляду явища та поняття канону як основи православної співочої традиції. Виявляється, що канонічну форму слід розуміти як форму, створену всередині традиції, всередині життя канону і під його безпосереднім впливом, що 
дозволяє розглядати канон як необхідну основу для богослужбової-співочого творчості.

Ключові слова: канон, канонічна форма, богослужбової-співоча традиція, культ, церковність.

Osadchaya S. Phenomenon and concept of the canon as basis of orthodox liturgical and singing tradition: from the initial form to «spirit of creativity». Article is devoted to consideration of the phenomenon and concept of a canon as bases of orthodox singing tradition. Comes to light that the initial form should be understood as the form created in tradition, in life of a canon and under his direct influence that allows to consider a canon as a necessary basis for liturgical and singing creativity.

Keywords: canon, initial form, liturgical and singing tradition, cult, churchism.

Стаття надійщла до редакції 27.04.2016

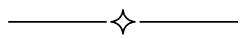

УДК $78.01+78.03$

\section{А. Овсянникова-Трель \\ ЭРОС И ЭТОС КАК ОБРАЗНЫЕ ДОМИНАНТЫ И ЦЕННОСТНЫЕ ОРИЕНТИРЫ МУЗЫКАЛЬНОГО ИСКУССТВА}

В статье обсуждается проблема воплощения образов Эроса и Этоса в музыке в аспекте культуротворческой функции музыкального искусства. Специально выделяется специфика художественного преломления образов Эроса и Этоса в академической и популярной музыке в контексте продуцирования ценностных ориентиров и смыслов культуры. Предлагаются направления культурологического исследования образов Эроса и Этоса как образных доминант и ценностных ориентиров музыкального искусства.

Ключевые слова: Эрос, Этос, музыкальное искусство, культурные ценности, академическая музыка, популярна музыка.

Музыка как форма культуры является механизмом отражения и продуцирования ценностных смыслов бытия человека. Соответственно, она неизбежно связана с базовыми основаниями человеческого сушествования, этическими по своей природе, и, в частности - отношением к Другому, взаимоотношением с Другим, потребностью «делиться собой» с Другим, в осознании своей абсолютной ценности для Другого, а также приятия себя этим Другим. Этическими - потому,

(C) Овсянникова-Трель А., 2016 